\title{
Relationship between Uterocervical Angle and Prediction of Spontaneous Preterm Birth
}

\author{
Original Ahmed Khairy Makled, Wessam Magdi Abuelghar, Mohammed Shaaban Abd Al \\ Article \\ Razik, Osama Ismail Kamel
}

Department of Obstetrics and Gynecology, Faculty of Medicine, Ain-Shams University, Cairo, Egypt

\begin{abstract}
Aim: This study aimed to determine whether a novel ultrasonographic marker, uterocervical angle, correlates with risk of spontaneous preterm birth.

Materials and Methods: In the present prospective, cohort, study, we included 197 singleton pregnant women at Ain shams university maternity hospital (outpatient obstetrics clinics and emergency department. The mean age of the included women was $27.2 \pm 4.8$ years while the mean party was $2.2 \pm 1.3$. The mean BMI was $33.4 \pm 2.6 \mathrm{Kg} / \mathrm{m} 2$.

Results: In the present study, we found that there were statistically significant differences between both groups in terms of history of preterm labor $(p<0.001)$ and tobacco smoking $(p=0.008)$. Smokers and women with history of PTB had higher risk of PTB. In our report, there were statistically significant differences between both groups in terms of neonatal mortality. With regard to the primary outcome of the present study, we found that there was statistically significant difference between women with spontaneous preterm labor and women with term deliveries regarding UCA $(p=0.015)$. Mean UCA in the second trimester was wider in the preterm group compared with the control group. The UCA was a significant discriminator of preterm labor. At cut-off value of $\geq 105$, the GP37 yielded a sensitivity of $86.7 \%$ and specificity of $89 \%$ for the discrimination between preterm and term deliveries.

Conclusion: Wider UCA in the second trimester is related to spontaneous PTB. UCA measurement is a reproducible technique. UCA appears to increase from the first to the second trimester.
\end{abstract}

Key Words: Spontaneous preterm birth, ultrasound, uterocervical angle

Received: 28 June 2021, Accepted: 12 July 2021

Corresponding Author: Mohammed Shaaban Abdel-Razik, Department of Obstetrics and Gynecology, Faculty of Medicine, Ain-Shams University, Cairo, Tel.: 01098988160, E-mail: mshabaan1877@gmail.com

ISSN: 2090-7265, August 2021, Vol.11, No. 3

\section{INTRODUCTION}

The World Health Organisation (WHO) defines preterm birth as any birth after 20 weeks and before 37 completed weeks of gestation, or fewer than 259 days since the first day of the woman's last menstrual period (LMP $)^{[1]}$.

Preterm birth (PTB) is a leading cause of perinatal morbidity and mortality and is estimated to complicate approximately $10-12 \%$ of pregnancies ${ }^{[2]}$.

To date, the optimal strategy of pregnancies at risk of preterm birth remains unclear. Progesterone, cervical cerclage, and the Arabin pessary have been used as potential management strategies in women with singleton pregnancies with a short cervix and history of previous spontaneous preterm birth $^{[3]}$.

Screening of pregnancies remains also problematic as the majority of current strategies is far from an optimal diagnostic accuracy. Fetal fibronectin has been suggested as a potential biomarker for the prevention of preterm birth; however, its sensitivity is relatively low $(34 \%)^{[4,5]}$.

Prematurity rates have changed little in recent years owing to the lack of effective methods of detecting patients at risk for preterm birth and appropriate tools to reduce this risk $^{[6]}$.

Angles between the uterus and cervix may be related to gestational age at delivery ${ }^{[7]}$.

Evidence exists that ultrasonographic measurement of cervical length (CL) in the second trimester of pregnancy and maternal history can help to identify women at risk for $\mathrm{SPTB}^{[8]}$.

Current guidelines suggest that women with a history of spontaneous preterm delivery or second trimester loss, as well as those with a short cervix $(<25 \mathrm{~mm})$ in a transvaginal ultrasound scan between 16 and 24 weeks of gestation should be offered treatment with cerclage or progesterone $e^{[9]}$. 


\section{AIM OF THE WORK}

Research hypothesis: Increase width of the uterocervical angle has been proposed to increase risk of spontaneous preterm birth.

Research question: Is Uterocevical angle accurate tool in predicting spontaneous preterm birth?

Aim: To determine whether a novel ultrasonographic marker, uterocervical angle, correlates with risk of spontaneous preterm birth.

\section{PATIENTS AND METHODS}

Ethical Statement: The study was approved by the Ethical Committee of the Faculty of Medicine, Ain Shams University. Informed consents were signed by all participants after simple and clear explanation of the research objectives and procedures. The consent form was developed according to the standard of Quality Improvement System implemented by Ministry Of Health and Population in Egypt.

Subjects: The current study was a prospective, cohort, study that included 197 singleton pregnant women at Ain-Shams University Maternity Hospital (Outpatient Obstetrics Clinics and Emergency Department) fulfilling the inclusion criteria during time period of January 2019 to December 2019.

Inclusion criteria included maternal age (18-40), BMI (20-34), singleton gestations between (18-28) weeks, multiparity, history of previous preterm deliveries or midtrimesteric abortions.

Exclusion criteria included loss of follow up, preterm premature rupture of membranes(PPROM),placental abnormalities, past history of cervical operations, multifetal pregnancy, polyhydramnios, steroids intake, medically or obstetric indicated pregnancy termination, serious maternal or fetal problems and cerclage during current pregnancy before the screening.

Sample Size Calculation : The minimum sample size was calculated by using PASS software (PASS 11 citation: Hintze J (2011). PASS 11. NCSS, LLC. Kaysville, Utah, USA). ROC curve analysis of uterocervical angle in the prediction of preterm labor had an area under curve equal to 0.655 , with $25 \%$ of cases had preterm labor. Based on this (197) cases were needed.

Data Collection: At baseline, each woman was evaluated as follows; complete history taking, clinical examination, routine antenatal laboratory investigations, including (blood group and Rh typing, full blood count and urine analysis), transvaginal ultrasound examination was performed at 18-28 weeks gestation in pregnant women with live singleton fetuses, attending routine prenatal care services.

After 20 weeks and before 37 weeks: Spontaneous preterm delivery was analyzed. The preterm labour was defined as regular contractions of the uterus resulting in changes in the cervix that start before 37 weeks of pregnancy. Changes in the cervix include effacement (the cervix thins out) and dilation (the cervix opens so that the fetus can enter the birth canal).

Women were followed up till the end of the pregnancy and gestational age at time of delivery were recorded. Accordingly, the pregnant women were assessed in 2 groups which were those delivered before (study group) and after (control group) 37 weeks of gestation.

Ultrasound Examination: Images were obtained from Ultrasound special care unit for the fetus in Ain Shams maternity hospital by the same sonographer to avoid interobserver fallacies of measure using the same sonography machine: SAMSUNG WS 80 Elite with vaginal probe (4- 9MHz) Made in Korea.

The UCA is the triangular segment measured between the lower uterine segment and the cervical canal, yielding a measurable angle (Figure 1).

The first ray was placed from the internal os to the external os. The calipers were placed where the anterior and posterior walls of the cervix touch the internal and external os along the endocervical canal. If the cervix was curved, the first ray was also drawn from the internal os to the external os as a straight line.

A second ray was then drawn to delineate the lower uterine segment. This ray was traced up the anterior uterine segment to a distance allowed by the preloaded image. Ideally, the second ray would reach $3 \mathrm{~cm}$ up the lower uterine segment in order to establish an adequate measurement.

The anterior angle in between the two rays was measured with a protractor. In the presence of funneling, the first ray was placed to measure the length of remaining cervix. The second caliper was placed from the innermost portion of measurable cervix and extended to the lower uterine segment.

In the event that the lower uterine segment was found to be irregular, the second caliper was placed centrally along the segment.

In the event of a retroverted uterus, the angle should be measured in a similar fashion with the first ray along the measurable cervix and the second ray traced along the lower uterine segment. Unlike in an anteverted or 
axial positioned uterus, however, the posterior side of the angle closer to the intrauterine contents should then be measured. Inter and intra-observer UCA measurements were compared for variability.

TVU CL was performed in a uniform fashion according to Cervical Length Education and Review (CLEAR) criteria by RDMS accredited sonographers who are monitored by Maternal Fetal Medicine attending staff.

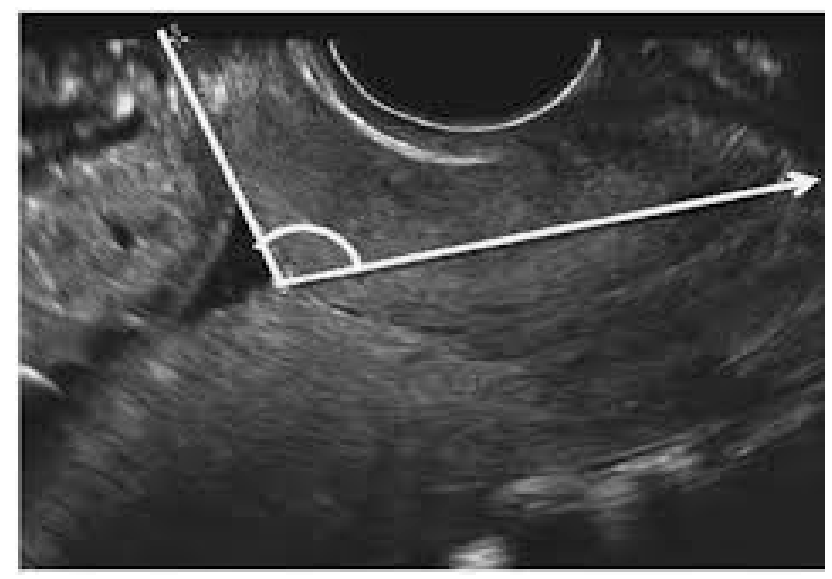

Fig.1: The UCA is the triangular segment measured between the lower uterine segment and the cervical canal

\section{STATISTICAL ANALYSIS:}

Data were collected, tabulated, statistically analyzed using an IBM personal computer with Statistical Package of Social Science (SPSS) version 20 and Epi Info 2000 programs, where the following statistics were applied.

\section{RESULTS}

The baseline demographic characteristics of the mothers was shown in Table 1 . The mean age of the included women was $27.2 \pm 4.8$ years while the mean party was $2.2 \pm 1.3$. The mean BMI was $33.4 \pm 2.6 \mathrm{Kg} / \mathrm{m}^{2}$.

The comparison of baseline demographics between preterm and term labor was presented in Table 2. There were no statistically significant differences between the both groups in terms of age $(p=0.31)$, BMI $(p=0.35)$ and parity $(p=0.09)$.

The comparison of baseline demographics between preterm and term labor was illustrated in Table 3. On the other hand, there was no statistically significant differences between both groups in terms of mode of delivery $(p=0.21)$.

The comparison of ultrasound parameters between preterm and term labor was shown in Table 4. There were statistically significant differences between women with spontaneous preterm labor and women with term deliveries regarding UCA $(p=0.015)$ and cervical length $(p=0.018)$. Mean UCA in the second trimester was wider in the preterm group compared with the control group. In addition, women with preterm delivers had lower cervical length than women with term delivers.

The diagnostic performance of UCA and CL was shown in Table 5. The UCA was a significant discriminator of preterm labor. At cut-off value of $\geq 105$, the UCA yielded a sensitivity of $86.7 \%$ and specificity of $89 \%$ for the discrimination between preterm and term deliveries. Similarly, at cut-off value of $\leq 25 \mathrm{~mm}$, the CL yielded a sensitivity of $83.3 \%$ and specificity of $74 \%$ for the discrimination between preterm and term deliveries.

Table 1: Shows the baseline demographic characteristics of the mothers

\begin{tabular}{lc}
\hline Variables & Patients $(\mathrm{N}=197)$ \\
\hline Age of the mother (years) & No \\
- Mean \pm SD & $27.2 \pm 4.8$ \\
- Median (Range) & $28(20-35)$ \\
BMI $(\mathrm{Kg} / \mathrm{m} 2)$ & $26.1 \pm 0.46$ \\
- Mean \pm SD & $26(21-29)$ \\
- Median (Range) & \\
Party, No. (\%) & $2.2 \pm 1.3$ \\
- Mean (SD) & $2(1-6)$ \\
\hline
\end{tabular}


Table 2: Shows the comparison of baseline demographics between preterm and term labor

\begin{tabular}{lcc}
\hline Variables & Preterm $(\mathrm{N}=53)$ & Term Labor $(\mathrm{N}=144)$ \\
\hline Age of the mother (years) & & \\
- Mean \pm SD & $28.5 \pm 6.1$ & $26.9 \pm 2.7$ \\
- Median (Range) & $28(21-35)$ & $27(20-35)$ \\
BMI (Kg/m2) & $25.9 \pm 4.4$ & $26.1 \pm 1.46$ \\
- Mean \pm SD & $24(21-29)$ & $26(21-29)$ \\
- Median (Range) & & \\
Party, No. (\%) & $3.2 \pm 1.3$ & $2.1 \pm 2.3$ \\
- Mean (SD) & $3(1-6)$ & $2(1-6)$ \\
- Median (Range) & & 0.35 \\
\hline
\end{tabular}

Table 3: Shows the comparison of fetal outcomes between preterm and term labor

\begin{tabular}{|c|c|c|c|c|c|}
\hline \multirow{2}{*}{ Variables } & \multicolumn{2}{|c|}{ Preterm $(\mathrm{N}=53)$} & \multicolumn{2}{|c|}{ Term Labor $(\mathrm{N}=144)$} & \multirow{2}{*}{ P-value } \\
\hline & No & $\%$ & No & $\%$ & \\
\hline $\begin{array}{l}\text { Gestational Age at delivery (Weeks) } \\
\text {-Mean (SD) } \\
\text {-Median (Range) }\end{array}$ & \multicolumn{2}{|c|}{$\begin{array}{c}34.9 \pm 4.2 \\
34(31-37)\end{array}$} & \multicolumn{2}{|c|}{$\begin{array}{c}38.4 \pm 1.6 \\
38(37-39)\end{array}$} & $<0.001$ \\
\hline $\begin{array}{l}\text { Mode of delivery, No. }(\%) \\
\text { - NVD } \\
\text { - CS }\end{array}$ & $\begin{array}{l}35 \\
18\end{array}$ & $\begin{array}{l}66.1 \\
33.9\end{array}$ & $\begin{array}{c}108 \\
36\end{array}$ & $\begin{array}{l}75 \\
25\end{array}$ & 0.21 \\
\hline $\begin{array}{l}\text { Status, No. }(\%) \\
\text { - Alive } \\
\text { - Dead }\end{array}$ & $\begin{array}{l}33 \\
20\end{array}$ & $\begin{array}{l}62.3 \\
37.7\end{array}$ & $\begin{array}{c}130 \\
14\end{array}$ & $\begin{array}{c}90.3 \\
9.7\end{array}$ & $<0.001$ \\
\hline
\end{tabular}

Table 4: Shows the comparison of ultrasound parameters between preterm and term labor

\begin{tabular}{|c|c|c|c|c|c|}
\hline \multirow{2}{*}{ Variables } & \multicolumn{2}{|c|}{ Preterm $(\mathrm{N}=53)$} & \multicolumn{2}{|c|}{ Term Labor $(\mathrm{N}=144)$} & \multirow{2}{*}{$P$-value } \\
\hline & No. & $\%$ & No. & $\%$ & \\
\hline $\begin{array}{l}\text { UCA at } 2^{\text {nd }} \text { Trimest } \\
\text { - Mean } \pm \text { SD } \\
\text { - Median (Range) }\end{array}$ & \multicolumn{2}{|c|}{$\begin{array}{c}105.16 \pm 21.6 \\
104(101.1-111.2)\end{array}$} & \multicolumn{2}{|c|}{$\begin{array}{c}94.5 \pm 22.7 \\
89(87-105.4)\end{array}$} & 0.015 \\
\hline \multicolumn{6}{|c|}{ UCA at $2^{\text {nd }}$ Trimester } \\
\hline$-\geq 105$ & 28 & 52.8 & 33 & 22.9 & 0.008 \\
\hline$-<105$ & 25 & 47.2 & 111 & 77.8 & \\
\hline \multicolumn{6}{|l|}{$\mathrm{CL}$ in $\mathrm{mm}$} \\
\hline $\begin{array}{l}\text { - Mean } \pm \text { SD } \\
\text { - Median (Range) }\end{array}$ & \multicolumn{2}{|c|}{$\begin{array}{c}31.3 \pm 8.5 \\
32(24-38)\end{array}$} & \multicolumn{2}{|c|}{$\begin{array}{c}36.8 \pm 5.6 \\
34(28-36)\end{array}$} & 0.018 \\
\hline \multicolumn{6}{|l|}{$\mathrm{CL}$ at $2^{\text {nd }}$ Trimester } \\
\hline & 5 & 9.1 & 0 & 0 & 0.001 \\
\hline $\begin{array}{l}-\leq 25 \mathrm{~mm} \\
->25 \mathrm{~mm}\end{array}$ & 48 & 90.9 & 144 & 100 & \\
\hline
\end{tabular}

Table 5: Shows the area under the curve and the diagnostic accuracy of UCA and CL

\begin{tabular}{llllll}
\hline Variable & AUC, 95\% CI & P-value & Cut-off points & Sensitivity & Specificity \\
\hline UCA & $0.96(0.92-0.99)$ & 0.001 & $\geq 105$ & $86.7 \%$ & $89 \%$ \\
CL & $0.83(0.72-0.93)$ & 0.001 & $\leq 25 \mathrm{~mm}$ & $83.3 \%$ & $74 \%$ \\
\hline
\end{tabular}

AUC: area under curve; CI: Confidence interval. 


\section{DISCUSSION}

Preterm birth (PTB), defined as delivery before completing 37 weeks' gestation, is a growing global public health problem. PTB is the leading cause of mortality in children under 5 years of age, and is a direct cause of at least $27 \%$ of all neonatal deaths. Of the live births reported in 2010 worldwide, $11.1 \%$, or 14.9 million, were estimated to be $\mathrm{PTBs}^{[10]}$.

Screening of pregnancies remains also problematic as the majority of current strategies is far from an optimal diagnostic accuracy. Fetal fibronectin has been suggested as a potential biomarker for the prevention of preterm birth; however, its sensitivity is relatively low (34\%). Current data also suggest that cervical length (CL) measurement may help identify these women as it may accurately predict pregnancies at risk of preterm birth. In this line, current guidelines suggest that women with a history of spontaneous preterm delivery or second trimester loss, as well as those with a short cervix $(<25 \mathrm{~mm})$ in a transvaginal ultrasound scan between 16 and 24 weeks of gestation should be offered treatment with cerclage or progesterone ${ }^{[11]}$.

Uterocervical angle (UCA) represents a novel ultrasonographic marker that is defined as the triangular segment measured between the lower uterine segment and the cervical canal. It is measured using a line that starts from the internal cervical os (that is extended along the cervical canal) and a second line that tracks the internal segment of the anterior uterine wall. During the last years several studies investigated the potential impact of UCA for the prediction of preterm birth. The rationale behind the hypothesis of this association is based on the potential mechanical properties of this angle, which seems to act as a preventive barrier when it is acute ${ }^{[12]}$.

However, there is a scarcity in the published literature which determine whether the UCA correlates with the risk of spontaneous preterm birth PTB. Therefore, we performed the present prospective study in order to evaluate the ability of second trimester UCA to predict spontaneous PTB in at-risk singleton pregnant women.

In the present prospective, cohort, study, we included 197 singleton pregnant women at Ain-Shams university maternity hospital (outpatient obstetrics clinics and emergency department. The mean age of the included women was $27.2 \pm 4.8$ years while the mean party was $2.2 \pm 1.3$. The mean BMI was $33.4 \pm 2.6 \mathrm{Kg} / \mathrm{m} 2$.

Risk factors for preterm birth include a history of preterm birth, short cervix, infection, short interpregnancy interval, smoking, and African- American race.
In the present study, we found that there were statistically significant differences between both groups in terms of history of preterm labor $(p<0.001)$ and tobacco smoking $(p=0.008)$. Smokers and women with history of PTB had higher risk of PTB.

Similar to our findings, Butali and colleagues ${ }^{[13]}$ performed a retrospective study on 5561 records in order to identify characteristics associated with PTB at the Lagos University Teaching Hospital (LUTH), Lagos, Nigeria from 2011 to 2013. The authors reported that smoking and history of PTB were significantly associated with increased risk of PTB.

In addition, Iyoke and colleagues ${ }^{[14]}$ performed retrospective review of singleton preterm and term births from January 2009 to December 2013, the majority of women were either primparous or multiparous and the most of them were delivered by cesarean section. The authors reported that smoking and history of PTB were significantly associated with increased risk of PTB.

The significance of PTB lies in the complications of prematurity sustained by the infant and the impacts of these complications on the infant's survival and subsequent development. The leading causes of infant mortality in the United States are preterm birth, low birth weight, and birth defects; so preterm birth and low birth weight are major contributors to infant mortality ${ }^{[15]}$.

In our report, there were statistically significant differences between both groups in terms of neonatal mortality.

Notably, D'Onofrio and colleagues ${ }^{[16]}$ estimate the extent to which the associations between early gestational age and offspring mortality and morbidity are the result of confounding factors. The authors conducted a population-based cohort study, combining Swedish registries to identify all individuals born in Sweden from 1973 to 2008 (3,300,708 offspring of 1,736,735 mothers) and link them with multiple outcomes. The results showed that there was a dose-response relationship between risks of PTB and infant mortality.

Cupen and colleagues ${ }^{[17]}$ examined the neonates who were delivered prematurely, at gestational age less than 37 weeks, and admitted to neonatal intensive care unit (NICU) for the period 1 January to 31 December 2015. The authors reported that $12 \%$ of the infants died after being admitted to the NICU.

With regard to the primary outcome of the present study, we found that there was statistically significant difference between women with spontaneous preterm 
labor and women with term deliveries regarding UCA ( $p=0.015)$. Mean UCA in the second trimester was wider in the preterm group compared with the control group. The UCA was a significant discriminator of preterm labor. At cut-off value of $\geq 105$, the GP37 yielded a sensitivity of $86.7 \%$ and specificity of $89 \%$ for the discrimination between preterm and term deliveries.

In concordance with our findings, Llobet and colleagues $^{[18]}$ assessed the ability of the UCA to predict spontaneous preterm birth before 34 and 37 weeks of gestation. A prospective cohort study with singleton pregnancies between 19.0 and 22.6 weeks of gestation. Mean UCA in the second trimester was wider in the preterm group compared with the control group.

Likewise, Lynch and colleagues ${ }^{[19]}$ aimed to determine if there is an association between UCA and SPTB $<37$ weeks. Retrospective cohort study from 2014 to 2017 of pregnancies with cervical length (CL) screening between 15 and 24 weeks was conducted. The mean UCA was significantly lower for delivery $\geq 37$ weeks compared to delivery $<37$ weeks.

Sur and colleagues ${ }^{[20]}$ performed a prospective observational study to evaluate the UCA of the uterus by transvaginal sonography and to determine the feasibility to predict spontaneous PTB. The duration of the study was from December 2014 to December 2016. The participants included 100 pregnant women with singleton pregnancy who were asymptomatic. The difference of mean cervical angle in women who delivered preterm and that of those who delivered at term in the $1 \mathrm{st}$ trimester (preterm group $114.2^{\circ}$ vs term group $\left.93.0^{\circ}, P<0.001\right)$ and in the $2^{\text {nd }}$ trimester (preterm group $127.66^{\circ}$ vs term group $\left.103.65^{\circ}, P<0.001\right)$ was significant. An ACA of $114.2^{\circ}$ in the $1^{\text {st }}$ trimester was associated with a risk of spontaneous preterm birth ( $P$ value 0.0065 , sensitivity $90 \%$ and specificity $80 \%$ ).

Vielba and colleagues ${ }^{[21]}$ assessed the ability of UCA compared with cervical length to predict the risk of spontaneous PTB. The authors conducted a retrospective cohort study of twin pregnancies undergoing transvaginal ultrasound between 19-21 weeks. A total of 177 women were included. ROC curves showed a better area under the curve (AUC) for UCA at all gestational ages compared with cervical length.

Llobet and colleagues ${ }^{[22]}$ aimed to determine whether the UCA correlates with the risk of spontaneous PTB and assess its interobserver variability. Case control study of 275 women including 34 who started labor spontaneously and gave birth before 34 weeks of gestation (preterm group) and 241 who gave birth at term (control group). Mean
UCA in the second trimester was wider in the preterm group $\left(105.16^{\circ}\right)$ compared with the control group $\left(94.53^{\circ}\right), p=.01$

On the contrary, Gründler and colleagues ${ }^{[23]}$ compared the test properties of CL and UCA on patients at risk for preterm birth. 109 patients with at least one of the following signs of threatening preterm birth between 20 and 31 weeks were included in a prospective cohort analysis. The $\mathrm{UCA}$ was on average $103^{\circ}$ and the mean UCA in preterm and term groups did not differ significantly $(P=.924)$. The UCA was not predictive for threatened preterm birth, even if only singletons were considered.

Likewise, Lynch and colleagues ${ }^{[24]}$ aimed to determine if change in UCA is associated with an increased rate of preterm birth (less than 37 weeks) for women with a short cervix. A retrospective study was performed from January 2013 to March 2016 of singleton pregnancies undergoing universal cervical length screening. A total of 176 women met the inclusion criteria. There was no difference in the rate of preterm birth at $<34$ weeks or at $<37$ weeks based on a change in UCA (i.e., decreased/ no change or increased UCA). However, women with a final UCA $>105$ degrees had an increased risk of preterm birth at less than 34 weeks.

The exact causes of such discrepancies between our findings and the abovementioned studies is unclear, however, it can be attributed to many factors. Firstly, the type of patients was heterogeneous across the abovementioned studies. Secondly, the sample size varied greatly among the abovementioned studies which may have attributed for such heterogeneity. The characteristics of the included women were apparently different which can be considered as another factor.

We acknowledge that the present study has a number of limitations. The sample size of the included patients was relatively small, which may affect the generalizability of our findings. Moreover, there were no long-term monitoring of the included women.

\section{CONCLUSION}

In conclusion, wider UCA in the second trimester is related to spontaneous PTB. UCA measurement is a reproducible technique. UCA appears to increase from the first to the second trimester. We recommend the introduce UCA in current clinical practice as a predictive factor that may be used for decision-making regarding management of women at risk of delivering preterm. Nonetheless, future studies are needed to evaluate the diagnostic accuracy of this index, and these should specifically consider the use of cut-off values and outcomes of interest (preterm birth rates based on specific gestational weeks). 


\section{CONFLICT OF INTEREST}

There are no conflicts of interests.

\section{REFERENCES}

1. Lynch TA, Szlachetka K and Seligman NS. "Ultrasonographic Change in Uterocervical Angle is not a Risk Factor for Preterm Birth in Women with a Short Cervix," American Journal of Perinatology, 2017; 34(11): 1058-1064.

2. Farr'as Llobet A, Reginc'os Mart'1 L, Higueras T, et al. The uterocervical angle and its relationship with pretermbirth. Journal of Maternal-Fetal \& Neonatal Medicine 2017; 31(14): 1881-1884.

3. Lynch TA, Szlachetka K, and Seligman NS. "465: Ultrasonographic measurement of uterocervical angle in twins: Predicting spontaneous preterm birth," American Journal of Obstetrics \& Gynecology, 2018; 218(1).

4. Sepúlveda-Martínez A, Díaz F, Muñoz H, et al. Second-Trimester Anterior Cervical Angle in a Low-Risk Population as a Marker for Spontaneous Preterm Delivery. Fetal. Diagn. Ther., 2016

5. Cannie MM, Dobrescu O, Gucciardo L, et al., Arabin cervical pessary in women at high risk of preterm birth: amagnetic resonance imaging observational follow-up study. Ultrasound Obstet. Gynecol 2013; 42: 426-433.

6. Mendoza M, Goya M, Gascón A, et al., Modification of cervical length after cervical pessary insertion: correlation weeks of gestation. J. Matern. Fetal. Neonatal. Med. 2016; 1-6.

7. Sochacki-Wójcicka N, Wojcicki J, BombaOpon D, et al. Anterior cervical angle as a new biophysical ultrasound marker for prediction of spontaneous preterm birth. Ultrasound in Obstetrics \& Gynecology 2015; 46: 377-378.

8. Knight JC, Tenbrink E, Sheng J, et al. Anterior uterocervical angle measurement improves prediction of cerclage failure. Journal of Perinatology 2017; 37(4): 375-379.

9. Dziadosz M. Uterocervical angle: a novel ultrasound screening tool to predict spontaneous preterm birth. Am. J. Obstet. Gynecol 2016.
10. Cobo T, Kacerovsky M, Jacobsson B. Risk factors for spontaneous preterm delivery. Int J Gynecol Obstet 2020; 150:17-23.

11. Daskalakis G, Theodora M, Antsaklis P, Sindos M, Grigoriadis T, Antsaklis A, Papantoniou $\mathrm{N}$, Loutradis D, Pergialiotis V. Assessment of Uterocervical Angle Width as a Predictive Factor of Preterm Birth: A Systematic Review of the Literature. Biomed Res Int 2018; 2018.

12. Sawaddisan R, Kor-anantakul O, Pruksanusak $\mathrm{N}$, Geater A. Uterocervical angle measurement for preterm birth prediction in singleton pregnant women with no history of preterm birth and normal cervical length: A prospective cohort study. Eur J Obstet Gynecol Reprod Biol 2020; 252:30-5.

13. Butali A, Ezeaka C, Ekhaguere O, Weathers N, Ladd J, Fajolu I, Esezobor C, Makwe C, Odusanya B, Anorlu R, Adeyemo W. Characteristics and risk factors of preterm births in a tertiary center in Lagos, Nigeria. Pan Afr Med J 2016;24.

14. Iyoke CA, Lawani LO, Ezugwu EC. Maternal risk factors for singleton preterm births and survival at the University of Nigeria Teaching Hospital, Enugu, Nigeria. Niger J Clin Pract 2015; 18:744-50.

15. Romero R, Dey SK, Fisher SJ. Preterm labor: One syndrome, many causes. Science (80) $2014 ; 345: 760-5$.

16. D’Onofrio BM, Class QA, Rickert ME, Larsson $\mathrm{H}$, Långström N, Lichtenstein P. Preterm birth and mortality and morbidity: A population-based quasi-experimental study. JAMA Psychiatry 2013; 70:1231-40.

17. Cupen K, Barran A, Singh V, Dialsingh I. Risk Factors Associated with Preterm Neonatal Mortality: A Case Study Using Data from Mt. Hope Women's Hospital in Trinidad and Tobago. Children 2017;4:108.

18. Llobet FA, Higueras T, Calero IZ, et al. Prospective evaluation of the uterocervical angle as a predictor of spontaneous preterm birth. Acta Obstet Gynecol Scand 2020; 99(11): 1511-8.

19. Lynch TA, Szlachetka K and Seligman NS. Second 
trimester uterocervical angle and spontaneous preterm birth in twins. J Matern Neonatal Med 2020;33:3125-31.

20. Sur B, Misra S and Dash S. Evaluation of the anterior cervical angle of the uterus to predict spontaneous preterm birth. Int J Reprod Contraception, Obstet Gynecol 2017; 6:2323.

21. Vielba BM, De Bonrostro Torralba C, Espiau RA. Uterocervical angle as a predictor of spontaneous preterm birth in twin pregnancies. J Matern Neonatal Med 2020; 1-8.

22. Llobet FA, Regincós Martí L, Higueras T, et al. The uterocervical angle and its relationship with preterm birth. J Matern Neonatal Med 2018; 31:1881-4.

23. Gründler K, Gerber B and Stubert J. Uterocervical angle as a predictor of preterm birth on a high-risk collective between 20 and 31 weeks of gestation: A cohort analysis. Acta Obstet Gynecol Scand 2020; 99(11): 1527-33.

24. Lynch TA, Szlachetka K and Seligman NS. Ultrasonographic Change in Uterocervical Angle is not a Risk Factor for Preterm Birth in Women with a Short Cervix. Am J Perinatol 2017; $34: 1058-64$. 